\title{
An evaluation of species richness estimators for tardigrades of the Great Smoky Mountains National Park, Tennessee and North Carolina, USA
}

\author{
Paul J. BARTELS* and Diane R. NELSON ${ }^{1)}$ \\ Department of Biology, Warren Wilson College, Asheville, NC 28815 - U.S.A. \\ ${ }^{1)}$ Department of Biological Sciences, East Tennessee State University, Johnson City, TN 37614 - U.S.A. \\ *e-mail corresponding author: pbartels@warren-wilson.edu
}

\begin{abstract}
For the past 5 years we have been conducting a large-scale, multi-habitat inventory of the tardigrades in the Great Smoky Mountains National Park (U.S.A.) as part of the All Taxa Biodiversity Inventory (ATBI) (see www.dlia.org). In terrestrial habitats, we collected moss, lichen, and soil samples from 19 permanent ATBI plots, representing all major land cover types within the park. Each ATBI plot is $100 \times 100 \mathrm{~m}$. In each plot, when available, 16 moss samples, 16 lichen samples, and 4 soil samples were collected in paper bags and air dried in the laboratory. Specimens were isolated with LudoxAM centrifugation, and for each sample up to 50 adults plus eggs were individually mounted on microscope slides in Hoyer's medium and identified using phase contrast and DIC microscopy. Additional collections were made in the limestone caves of the Cades Cove region of the park, bird nests, and 13 different streams. To date (1-Jun-06), 589 samples have been collected, and of these 401 have been analyzed, yielding a total of 8133 identifiable tardigrades or, in some cases, species groups. A total of 73 species have been found in the park, 14 of which we believe are new to science. Seven species richness estimators have been developed to predict total species richness (see EstimateS 7.5 software, viceroy.eeb.uconn.edu/estimates), and these were evaluated by comparing predictions from half of our data to the actual numbers from the total database. The results of this comparison indicate that different estimators work best in different habitats. Using the best estimators in each habitat, EstimateS 7.5 indicates that a total of 96 species are likely to occur throughout the park. Thus, Great Smoky Mountains National Park tardigrade diversity represents $10 \%$ of the world's known tardigrade fauna.
\end{abstract}

Key words: Meiofauna, biodiversity, species richness, biological inventory, Southern Appalachians

\section{INTRODUCTION}

Quantifying biodiversity is an essential part of conservation biology, yet it is an exceedingly difficult task, especially for cryptic organisms. A variety of methods have been developed in recent years to quantify biodiversity, yet very few studies have compared or evaluated these new techniques (Brose et al. 2003).

The Great Smoky Mountains National Park (GSMNP) U.S.A., a designated U.N. Biosphere Reserve, is renowned as one of the most biodiverse temperate forests in the world. Most of our knowledge of the park's biodiversity has been focused on macroscopic life, yet the park's micro-biota is relatively unknown and is likely to be equally or more diverse. Our inventory of the park's tardigrades (Phylum Tardigrada) is part of a much larger effort, the All Taxa Biodiversity Inventory (see www.dlia.org), whose goal is to catalogue all life within the park's boundaries. The database generated for this inventory provides an ideal tool for evaluating various species richness estimators.

Bartels \& Nelson (2006) presented a preliminary report of this large-scale, multi-habitat inventory for our first two field seasons (2001-2003). At that time, we had collected 420 samples from tree moss, tree lichen, stream sediment and periphyton, and soil/leaf litter. A few additional samples had been taken from caves, bird nests, and rock lichens and mosses. Sixty samples had been processed, leading to 1510 identified tardigrades representing 42 species. These included 39 new records for the park including 8 species believed to be new to science.

Estimating total biodiversity of cryptic species is not an easy task. Several species richness estimators have been developed in recent years, and these have become invaluable tools for biodiversity calculations and comparisons (Colwell \& Coddington 1994; Chazdon et al. 1998). Bartels \& Nelson (2006) calculated species richness using EstimateS software (Colwell 1997) for 1334 identifiable individuals. These estimates indicated that 47-76 species of tardigrades might exist in the GSMNP. Bartels \& Nelson (2006) also stated that as more data accumulated we would evaluate the seven different species richness estimators included in EstimateS to determine which was most accurate for tardigrade biodiversity predictions.

In this paper we provide an update on the results of our inventory. We believe this is the second largest inventory of tardigrades ever completed after Dastych (1980) who collected over 50,000 specimens in the Tatra National Park of Poland. We are maintaining our records in a geo-referenced database (Microsoft Access). We used our database to evaluate the various species richness estimators in EstimateS. The results of this evaluation are reported here, as well as updated species richness estimates for the park with a discussion 


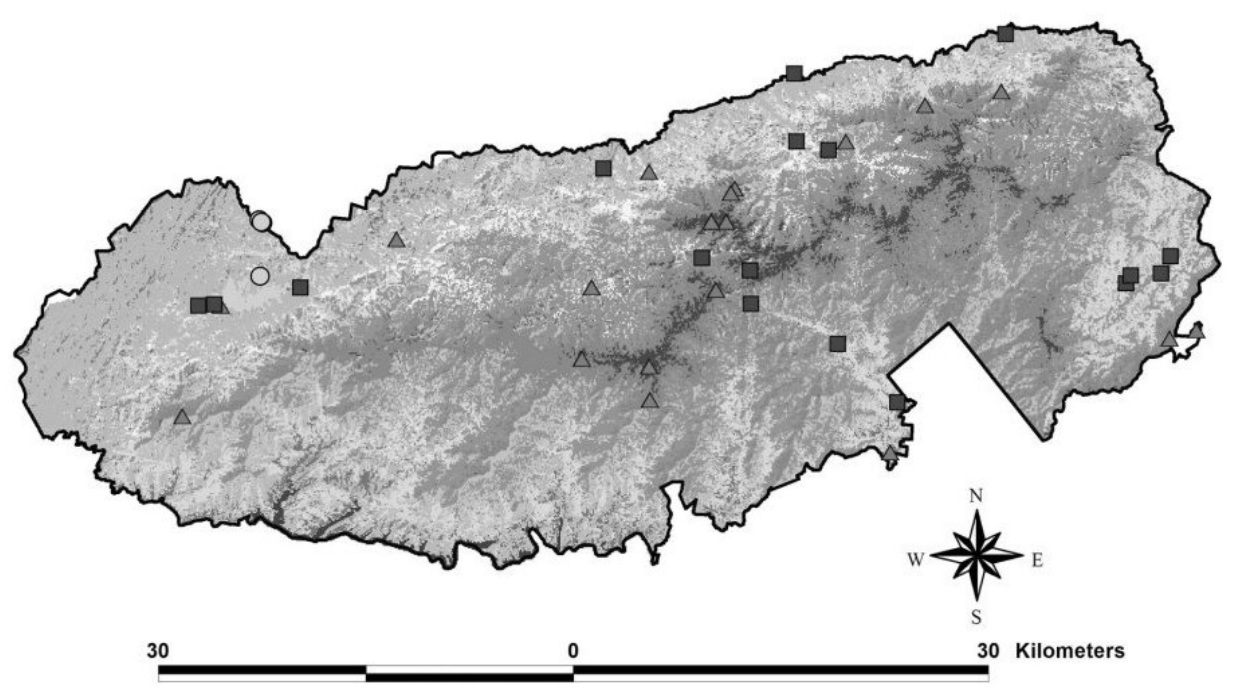

Fig. 1. Vegetation map of the GSMNP with collection sites. Shades of gray indicate various vegetation zones. Squares are aquatic sampling sites, circles are cave sites, and triangles are the permanent ATBI plots. The approximate center of the park is N $35^{\circ} 40^{\prime}, \mathrm{W}$ $83^{\circ} 20^{\prime}$.

of the relative diversity in the GSMNP versus other sites with large-scale inventories.

\section{METHODS}

Detailed methods for collecting samples and preparing specimens are given in Bartels \& Nelson (2006). Briefly, 19 permanent plots $(100 \times 100 \mathrm{~m})$ established for the All Taxa Biodiversity Inventory were sampled (Fig. 1). These represent all major land cover types, and various elevations, within the GSMNP. Locations and specifications for these plots can be found at www.discoverlifeinamerica.org. A complete set of samples from a plot included 4 soil samples, moss samples from breast height and ground level from 8 trees, which consisted of 4 American beech (Fagus grandifolia Ehrh.) and 4 yellow buckeye (Aesculus flava Sol.) when available, and lichen samples from breast height and ground level on the same trees. Thus, a full collection included 36 samples from each ATBI plot. Additional samples collected include cave sediments, bird nests, seeps, and rock lichens and mosses. Specimens from these are included in overall species lists (see "other" column of Tab. 1), but not in the species richness estimates. Terrestrial field samples were placed in paper bags and air-dried. They were processed in the lab with Ludox $^{\mathrm{AM}}$ centrifugation, and specimens were individually mounted in Hoyer's medium. Stream samples were collected from 13 streams in the park. These were processed immediately upon collection. A stream sample included 4 sediment samples and 4 periphyton samples from a given collection site. Up to 50 adults plus eggs, when available, were mounted per sample, and these were examined with phase and DIC microscopy.

Species richness was calculated with the statistical program EstimateS 7.5 (Colwell 1997). Because of rare species, observed species accumulation curves underes- timate species richness (Colwell \& Coddington 1994), so a number of estimates have been developed to predict true species richness (Chazdon et al. 1998). Throughout these calculations, we used 100 randomizations and patchiness set at 0 , which eliminates biases in the species richness estimates caused by species patchiness, which is characteristic of tardigrades. We used our updated database to calculate total species richness, and to evaluate the accuracy of the seven estimators included in EstimateS. These estimators are Chao 1, Chao 2, ACE, ICE, Jacknife 1, Jacknife 2, and Bootstrap. For these analyses, we analyzed the samples separately by habitat type (soil, moss, lichen, and streams) since the species richness estimators treat each individual sample as an independent and equivalent sampling unit. For the species richness estimator evaluation we selected half of the samples from each habitat type. For convenience, the samples selected were the first to be entered in the database. Species richness estimators were calculated for this subset and compared to the observed species in the entire dataset for each habitat type.

\section{RESULTS}

As of 1-Jun-06, we have examined 9125 slides, yielding 8133 tardigrades identifiable to species (or in some cases species groups). These specimens came from 401 samples (116 moss, 86 lichen, 66 soil, 103 aquatic, 30 other) from all 19 ATBI plots in addition to 13 streams, 3 caves, 4 bird nests, and a few seeps. Processing is still in progress, so many more samples await identifications. See Figure 1 for map of collecting sites.

Our current species list now stands at 73 (Tab. 1). Seventy of these are new records for the park. We are reasonably sure that at least 14 of our species are new to science, and we are now beginning to describe these. 
Tab. 1. Species list and habitat associations. Some species identifications remain to be confirmed. "Other" habitat includes cave sediments, bird nests, and seeps.

\begin{tabular}{|c|c|c|c|c|c|c|}
\hline \multirow{2}{*}{$\frac{\text { Family }}{\text { Echiniscidae }}$} & \multirow{2}{*}{$\begin{array}{l}\text { Species } \\
\text { Bryodelphax } \mathrm{n} . \mathrm{sp} .\end{array}$} & \multirow[t]{2}{*}{ Moss } & \multicolumn{3}{|c|}{ Lichens Soil/Leaf Litter Aquatic } & \multirow[t]{2}{*}{ Other } \\
\hline & & & $\mathrm{X}$ & & & \\
\hline & Echiniscus horningi Schuster \& Grigarick, 1971 & $\mathrm{X}$ & $\mathrm{X}$ & $\mathrm{X}$ & & \\
\hline & Echiniscus mauccii Ramazzotti, 1956 & $\mathrm{X}$ & $\mathrm{X}$ & $\mathrm{X}$ & & \\
\hline & Echiniscus mosaicus Grigarick, Schuster \& Nelson, 1983 & & $\mathrm{X}$ & & & \\
\hline & Echiniscus perviridis Ramazzotti, 1959 & & & & & $\mathrm{X}$ \\
\hline & Echiniscus virginicus Riggin, 1962 & $\mathrm{X}$ & $\mathrm{X}$ & $\mathrm{X}$ & & \\
\hline & Echiniscus viridis Murray, 1910 & & $\mathrm{X}$ & & & $\mathrm{X}$ \\
\hline & Hypechiniscus gladiator gladiator (Murray, 1907) & $\mathrm{X}$ & $\mathrm{X}$ & $\mathrm{X}$ & & \\
\hline & Pseudechiniscus brevimontanus Kendall-Fite \& Nelson, 1996 & $\mathrm{X}$ & $\mathrm{X}$ & $\mathrm{X}$ & & \\
\hline & Pseudechiniscus n. sp. & $\mathrm{X}$ & $\mathrm{X}$ & & & \\
\hline & Pseudechiniscus suillus group & $\mathrm{X}$ & $\mathrm{X}$ & $\mathrm{X}$ & & \\
\hline Calohypsibiidae & Calohypsibius schusteri Nelson \& McGlothlin, 1996 & $\mathrm{X}$ & $\mathrm{X}$ & $\mathrm{X}$ & & \\
\hline \multirow{2}{*}{ Eohypsibiidae } & Amphibolus cf. smreczinskii & & & $\mathrm{X}$ & & \\
\hline & Amphibolus cf. weglarskae & $\mathrm{X}$ & & & & \\
\hline \multirow{40}{*}{ Hypsibiidae } & Astatumen trinacriae (Arcidiacono, 1962) & $\mathrm{X}$ & $\mathrm{X}$ & $\mathrm{X}$ & & $\mathrm{X}$ \\
\hline & Diphascon (Adropion) belgicae Richters, 1911 & & & $\mathrm{X}$ & & \\
\hline & Diphascon (Adropion) scoticum scoticum Murray, 1905 & $\mathrm{X}$ & $\mathrm{X}$ & $\mathrm{X}$ & $\mathrm{X}$ & $\mathrm{X}$ \\
\hline & Diphascon (Adropion) cf. carolae & $\mathrm{X}$ & & $\mathrm{X}$ & & \\
\hline & Diphascon (Diphascon) cf. ramazzottii & $\mathrm{X}$ & & & & \\
\hline & Diphascon (Diphascon) granifer Greven, 1972 & & & & $\mathrm{X}$ & \\
\hline & Diphascon (Diphascon) higginsi Binda, 1971 & $\mathrm{X}$ & $\mathrm{X}$ & $\mathrm{X}$ & $\mathrm{X}$ & $\mathrm{X}$ \\
\hline & Diphascon (Diphascon) nobilei Binda, 1969 & & & $\mathrm{X}$ & & \\
\hline & Diphascon (Diphascon) nodulosum (Ramazzotti, 1957) & $\mathrm{X}$ & $\mathrm{X}$ & $\mathrm{X}$ & & \\
\hline & Diphascon (Diphascon) patanei Binda \& Pilato, 1971 & $\mathrm{X}$ & $\mathrm{X}$ & $\mathrm{X}$ & $\mathrm{X}$ & \\
\hline & Diphascon (Diphascon) pingue pingue (Marcus, 1936) & $\mathrm{X}$ & $\mathrm{X}$ & $\mathrm{X}$ & & $\mathrm{X}$ \\
\hline & Doryphoribius cf. zappalai & & & & $\mathrm{X}$ & $\mathrm{X}$ \\
\hline & Doryphoribius n. sp. & & & $\mathrm{X}$ & & $\mathrm{X}$ \\
\hline & Doryphoribius sp. 1 & & & & $\mathrm{X}$ & \\
\hline & Doryphoribius sp. 2 & & $\mathrm{X}$ & & & \\
\hline & Hypsibius convergens (Urbanowicz, 1925) & $\mathrm{X}$ & $\mathrm{X}$ & $\mathrm{X}$ & $\mathrm{X}$ & $\mathrm{X}$ \\
\hline & Hypsibius dujardini (Doyère, 1840) & & & $\mathrm{X}$ & $\mathrm{X}$ & $\mathrm{X}$ \\
\hline & Hypsibius roanensis Nelson \& McGlothlin, 1993 & $\mathrm{X}$ & $\mathrm{X}$ & $\mathrm{X}$ & & \\
\hline & Isohypsibius cf. basalovoi & & & $\mathrm{X}$ & & \\
\hline & Isohypsibius $\mathrm{cf}$. brevispinosus & & & $\mathrm{X}$ & & \\
\hline & Isohypsibius cf. deconincki & & & & $\mathrm{X}$ & \\
\hline & Isohypsibius granulifer granulifer Thulin, 1928 & & & $\mathrm{X}$ & $\mathrm{X}$ & \\
\hline & Isohypsibius lunulatus (Iharos, 1966) & $\mathrm{X}$ & & $\mathrm{X}$ & $\mathrm{X}$ & \\
\hline & Isohypsibius $\mathrm{n} . \mathrm{sp} .1$ & $\mathrm{X}$ & & $\mathrm{X}$ & $\mathrm{X}$ & \\
\hline & Isohypsibius n. sp. 2 & & & $\mathrm{X}$ & $\mathrm{X}$ & \\
\hline & Isohypsibius n. sp. 3 & & & & $\mathrm{X}$ & \\
\hline & Isohypsibius n. sp. 4 & & & & $\mathrm{X}$ & \\
\hline & Isohypsibius n. sp. 5 & & & & $\mathrm{X}$ & $\mathrm{X}$ \\
\hline & Isohypsibius sattleri Richters, 1902 & & & $\mathrm{X}$ & $\mathrm{X}$ & \\
\hline & Isohypsibius tuberculatus group & $\mathrm{X}$ & & $\mathrm{X}$ & $\mathrm{X}$ & $\mathrm{X}$ \\
\hline & Itaquascon $\mathrm{n} . \mathrm{sp}$. & & $\mathrm{X}$ & $\mathrm{X}$ & & \\
\hline & Mesocrista cf. spitzbergensis & $\mathrm{X}$ & & $\mathrm{X}$ & & \\
\hline & Platicrista angustata (Murray, 1905) & & & $\mathrm{X}$ & & $\mathrm{X}$ \\
\hline & Platicrista horribilis Kaczmarek \& Michalczyk, 2003 & $\mathrm{X}$ & $\mathrm{X}$ & & & \\
\hline & Pseudobiotus n. sp. & & & & $\mathrm{X}$ & \\
\hline & Ramazzottius baumanni (Ramazzotti, 1962) & $\mathrm{X}$ & $\mathrm{X}$ & & & \\
\hline & Ramazzottius oberhaeuseri group & $\mathrm{X}$ & $\mathrm{X}$ & $\mathrm{X}$ & & $\mathrm{X}$ \\
\hline & Thulinius augusti (Murray, 1907) & & & & $\mathrm{X}$ & \\
\hline & Thulinius ruffoi Bertolani, 1981 (1982) & & & & $\mathrm{X}$ & \\
\hline & Thulinius stephaniae (Pilato, 1974) & & & & $\mathrm{X}$ & \\
\hline \multirow[t]{8}{*}{ Macrobiotidae } & Dactylobiotus cf. grandipes & & & & $\mathrm{X}$ & \\
\hline & Macrobiotus cf. crenulatus & $\mathrm{X}$ & $\mathrm{X}$ & & & \\
\hline & Macrobiotus cf. echinogenitus & $\mathrm{X}$ & & & & \\
\hline & Macrobiotus cf. liviae & $\mathrm{X}$ & $\mathrm{X}$ & $\mathrm{X}$ & & \\
\hline & Macrobiotus harmsworthi harmsworthi Murray, 1907 & & $\mathrm{X}$ & $\mathrm{X}$ & & $\mathrm{X}$ \\
\hline & Macrobiotus hufelandi group sp. 1 & $\mathrm{X}$ & $\mathrm{X}$ & $\mathrm{X}$ & & $\mathrm{X}$ \\
\hline & Macrobiotus hufelandi group sp. 2 & $\mathrm{X}$ & $\mathrm{X}$ & & & \\
\hline & Macrobiotus richtersi Murray, 1911 & $\mathrm{X}$ & $\mathrm{X}$ & $\mathrm{X}$ & & $\mathrm{X}$ \\
\hline
\end{tabular}


Tab. 1. Continuation.

\begin{tabular}{|c|c|c|c|c|c|c|}
\hline Family & Species & Moss & \multicolumn{3}{|c|}{ Lichens Soil/Leaf Litter Aquatic } & \multirow[t]{2}{*}{ Other } \\
\hline & Macrobiotus n. sp. 8 & $\mathrm{X}$ & & $\mathrm{X}$ & & \\
\hline & Macrobiotus n. s.p 9 & & & $\mathrm{X}$ & & \\
\hline & Macrobiotus tonollii Ramazzotti, 1956 & $\mathrm{X}$ & $\mathrm{X}$ & $\mathrm{X}$ & & $\mathrm{X}$ \\
\hline & Minibiotus intermedius (Plate, 1889) & $\mathrm{X}$ & $\mathrm{X}$ & $\mathrm{X}$ & & $\mathrm{X}$ \\
\hline & Minibiotus lazzaroi (Maucci, 1986) & $\mathrm{X}$ & $\mathrm{X}$ & & & \\
\hline & Minibiotus pustulatus (Ramazzotti, 1959) & $\mathrm{X}$ & $\mathrm{X}$ & & & \\
\hline & Murrayon cf. hastatus & & & & $\mathrm{X}$ & \\
\hline & Murrayon cf. pullari & & & & $\mathrm{X}$ & \\
\hline & Murrayon n. sp. & & & & $\mathrm{X}$ & \\
\hline & Murrayon stellatus Guidetti, 1998 & $\mathrm{X}$ & & & & \\
\hline Milnesiidae & Milnesium n. sp. & $\mathrm{X}$ & $\mathrm{X}$ & $\mathrm{X}$ & $\mathrm{X}$ & $\mathrm{X}$ \\
\hline
\end{tabular}

\section{a. Aquatic}

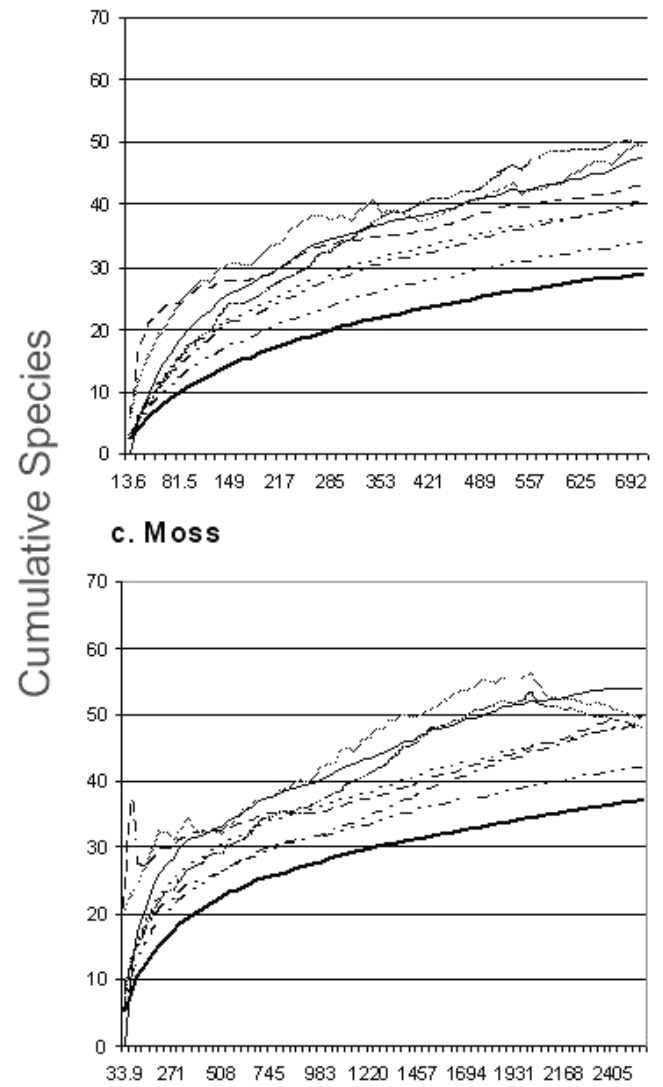

\section{b. Lichen}

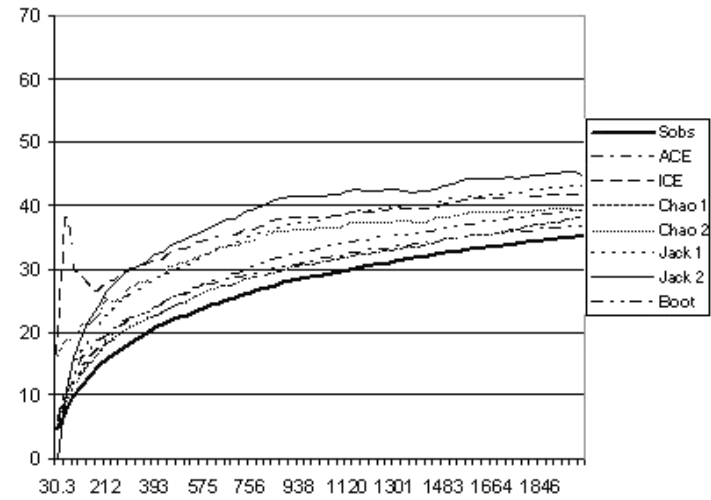

d. Soil

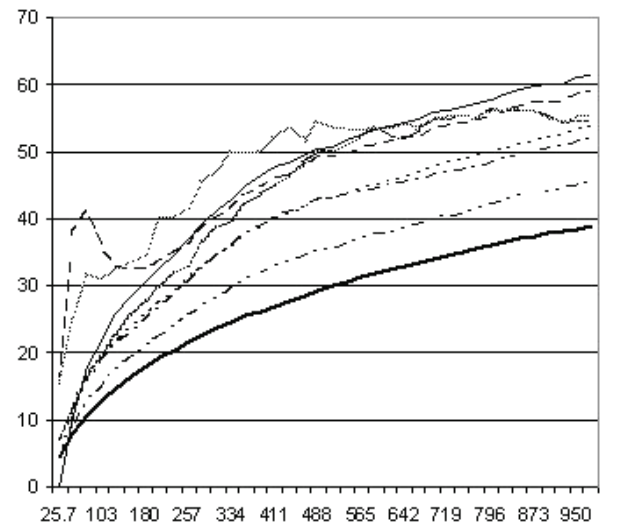

Individuals Identified

Fig. 2. Aquatic, lichen, moss, and soil species richness for tardigrades of the GSMNP. The observed species (= Sobs) accumulation curve is indicated by the black line. Gray lines are species richness estimate curves as indicated in the legend.

A remarkable number of our species are extremely rare in the park. Less than 8 individuals $(<0.01 \%$ of the total collection) have been found for 28 of the 73 species. It is these rare species that are likely to be missed by smaller inventories, and surely there are others to be found in the GSMNP. Thus, we calculated species accumulation curves and species richness estimates (Fig. 2). When these calculations were made, a total of 6220 individuals were available that were identified to species. These came from 231 samples of moss, lichen, soil, and stream substrates. The four graphs in this fig- ure show the species accumulation curve as a function of number of individuals identified. The seven species richness estimators are superimposed on each graph.

One way to develop a total species richness estimate for the park is to sum the species richness estimates for each habitat and subtract the number of species co-occurring in multiple habitats. Approximately 50\% of observed species co-occurred in multiple habitats (Tab. 2) so this value was used as an estimate to correct for cooccurrence in species richness estimates as well. Based on these calculations, the species richness estimates 
Tab. 2. Species observed and total species richness estimate for the GSMNP. Percent of duplicates in observed species was used as an estimate to correct for habitat co-occurrence in low and high species richness estimates. The low estimate was taken from the lowest of the 7 species richness estimators calculated by EstimateS 7.5 for each habitat, and the high estimate was taken from the highest of the species richness estimators for each habitat.

\begin{tabular}{lccc}
\hline Habitat & Observed & Low Estimate & High Estimate \\
\hline Aquatic & 29 & 34 & 49 \\
Soil & 39 & 52 & 61 \\
Lichen & 35 & 37 & 45 \\
Moss & 37 & 48 & 54 \\
Total & 140 & 171 & 209 \\
Sp. in Multiple Habitats & -70 & -85 (estimate) & -104 (estimate) \\
Adjusted Total & 70 & 86 & 105 \\
\hline
\end{tabular}

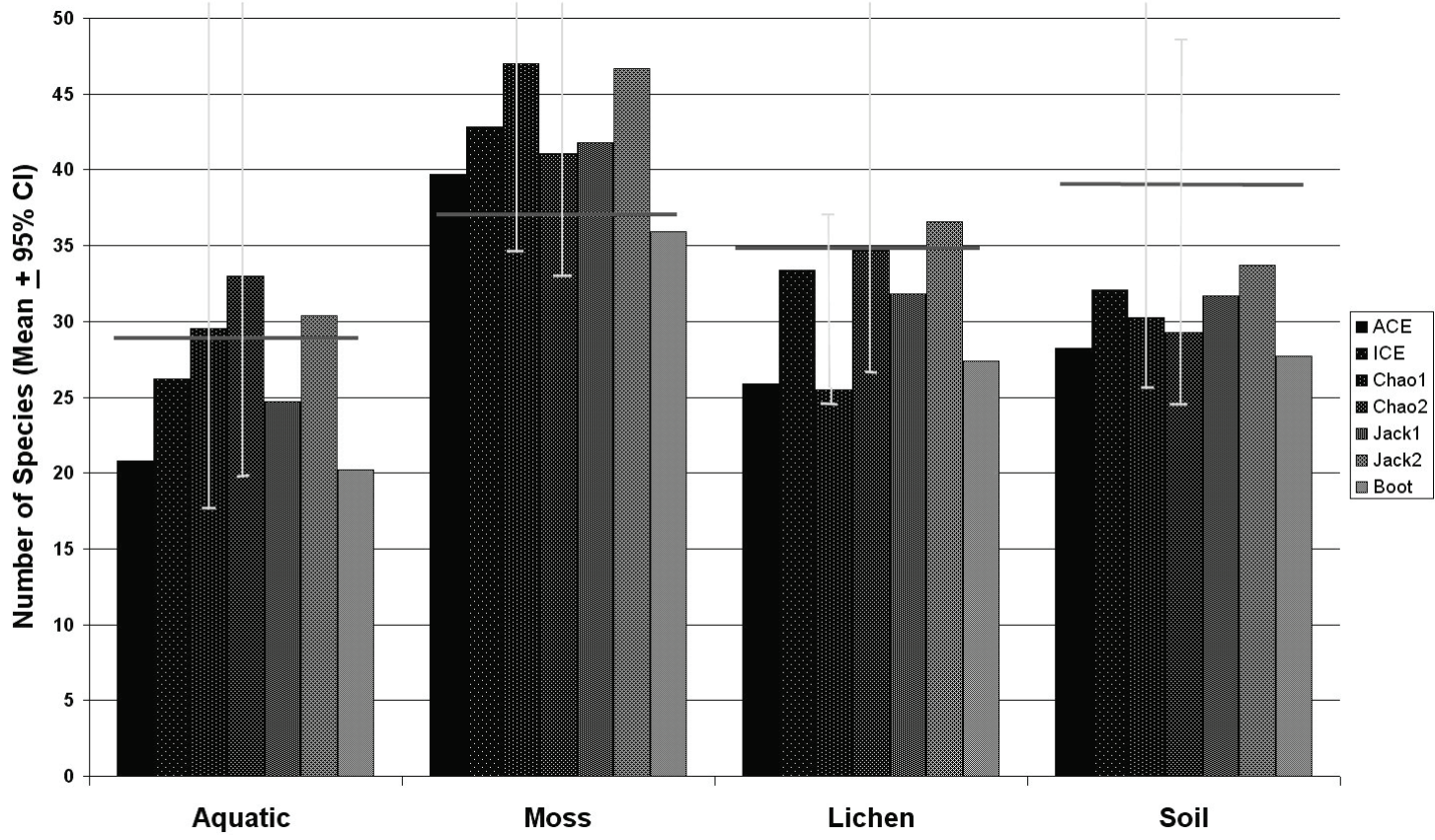

Fig. 3. Evaluation of species richness estimators. Each bar represents the asymptotic species richness estimate of one of the seven species richness estimators as calculated by EstimateS 7.5 using half of the dataset (3112 individuals). The horizontal bar is the observed species from the entire dataset (6224 individuals). Confidence intervals are given for Chao1 and Chao2 estimators.

indicate a range of 86-105 species for moss, lichen, soil, and stream habitats.

If we could determine that one of the estimators was more accurate than others, we could use those values to create a more accurate total species richness estimate. Thus, to evaluate the various estimators (Fig. 3), we compared the species richness estimates from half of the dataset (3112 individuals from 137 samples) with the observed species in the total dataset (6220 individuals from 231 samples). The graph shows the results for all four major habitats. For each habitat, the histograms indicate the seven species richness estimates for half of the dataset. The horizontal bars are the actual observed species in the total dataset for each habitat. Also note that for Chao I and II, 95\% confidence intervals are included. These are confidence intervals for the asymptotic species richness, thus in the positive direction they are quite large. The negative confidence interval is reduced because it cannot dip below the number of actual species observed.

It is clear from figure 3 that there is no single most accurate estimator. Different estimators appear to work best for different habitats, and all seriously undershot the actual observed number for soil samples. Still, it is possible to use the best estimator for each habitat, sum these estimates, subtract $50 \%$ for co-occurrence, and come up with a single species richness estimate. We selected Chao 1 for the aquatic samples, Bootstrap for the moss samples, Chao 2 for the lichen samples, and Jacknife 2 for the soil samples. The total species richness estimate based on this method is 96 .

\section{DISCUSSION}

Our current species list now stands at 73, 70 of which are new records for the GSMNP. Previously Diphascon pingue, Macrobiotus harmsworthi, and 
Tab. 3. Comparison of tardigrade diversity in large scale, multihabitat inventories. The Italian study was conducted by Bertolani \& Rebecchi (1996) and the Polish study by Dastych (1980).

\begin{tabular}{lcccc}
\hline & Italy 1996 & Poland 1980 & Smokies Current & Smokies Estimated \\
\hline Terrestrial & 29 & 54 & 55 & 70 \\
Aquatic & 10 & - & 15 & 25 \\
Total & 39 & - & 70 & 90 \\
Specimens & $\sim 1000$ & $\sim 50,000$ & $\sim 8000$ & $\sim 6220$ \\
\hline
\end{tabular}

Minibiotus intermedius were identified in the park by Riggin (1962). Total species richness estimated by Bartels \& Nelson (2006) ranged from 47-76 species of tardigrades for the GSMNP. Our current species list of 73, therefore, is already nearing the upper estimate of our previous predictions. Clearly our early species numbers were underestimates. With many more samples to process, and many species groups still to be separated (e.g. Minibiotus intermedius group and Macrobiotus hufelandi group), our species list will grow considerably.

Estimating total species richness is very difficult, and while several new tools have been developed, it is impossible to determine which are best suited to tardigrades. By comparing estimates made from half of our database to the total found in the complete database, we were able to evaluate the seven species richness estimators calculated by EstiamteS 7.5. This analysis indicates that no single estimator is accurate for all habitats. Indeed, for soil samples, all estimates seriously underestimated diversity. This may have been due to a nonrandom selection of samples when we halved the data, however, it is unknown why some estimators are better than others in any particular situation. Species richness estimates from our current dataset indicate a range of 86-105 species in the park. Using the best species richness estimator for each major habitat type, this estimate becomes 96 species. Although more work is needed to evaluate species richness estimators, this should be a more accurate measure than earlier reported by Bartels \& Nelson (2006).

Two other large-scale, multi-habitat inventories have been published previously (Dastych 1980; Bertolani \& Rebecchi 1996). Results from these studies are compared with our data in table 3 . Dastych investigated the Tatra National Park in Poland, and Bertolani \& Rebecchi worked in the Apennines Mountains of Italy. The Polish study included over 50,000 specimens from 1637 samples at 349 sites. The total species list included 54 species, but aquatic habitats were not sampled. The Italian investigation found 39 species, including terrestrial and aquatic tardigrades. This study took place on a fairly small site $\left(1 \mathrm{~km}^{2}\right)$ and included 967 specimens from 64 samples (Bertolani, personal communication).

Bartels \& Nelson (2006) concluded that diversity in the GSMNP appeared to be lower than that reported by Dastych (1980) and Bertolani \& Rebecchi (1996) and attributed this to the lack of a subalpine zone in the GSMNP. However, given our current species list and new species richness estimates, this conclusion must be reassessed.

It now appears that the GSMNP is at least as diverse as Tatra National Park, and probably more so. The exhaustive study by Dastych is likely to be a fairly complete inventory. The terrestrial tardigrade species in our sample outnumber those of Dastych (55 VS 54), while he identified over 50,000 specimens compared to our current total of 8133 . Furthermore, species richness estimates suggest an additional 15 terrestrial species might still be found in the GSMNP.

It is more difficult to compare tardigrade biodiversity in the GSMNP with the Italian study. Their site and their number of specimens were much smaller. We could compare species richness to total collection size. Bertolani \& Rebecchi (1996) found 39 species in a collection of 967 specimens (a species to specimen ratio of 0.04 ), whereas we found 73 species in a collection of 8133 specimens (a species to specimen ratio of 0.009 ). This would suggest that the diversity was higher in Italy, but that is very misleading since species accumulation curves level off with increased sampling effort. For example, Bartels \& Nelson (2006) reported 41 species out of 1510 specimens (a species to specimen ratio of 0.03 ), but now with 8133 specimens the ratio is 0.009 . This attempt to compare tardigrade fauna of three sites illustrates the need for species accumulation curves and species richness estimates. If species accumulation curves had been calculated for the two European studies, direct comparisons could be made.

\section{CONCLUSIONS}

Our current database of 8133 species from 401 samples, includes 73 species of tardigrades, 70 of which are new records for the GSMNP. Of these 14 are likely new to science. No single species richness estimator seems to work for tardigrades in all habitats, but when the best estimator for each habitat is used, a total species richness of 96 is predicted for the GSMNP. This is at least as diverse as the tardigrade fauna from intensive surveys at sites in Italy and Poland, and quite likely more so.

We are continuing to identify specimens from our collection, and when complete our database should contain 12,000-15,000 specimens. As datasets are completed for the various habitat types, multivariate analysis will allow us to determine the key ecological variables controlling the distribution and diversity of tardigrades in the GSMNP. 


\section{ACKNOWLEDGMENTS}

We would like to thank Discover Life in America for financial support. Gilbert Hale made most of the slides, and over 20 eager and energetic undergraduates from Warren Wilson College assisted in a wide variety of lab and data processing. Nigel Marley and Sandra McInnes assisted in some species identifications.

\section{REFERENCES}

Bartels, P.J. \& D.R. Nelson. 2006. A large-scale, multihabitat inventory of the Phylum Tardigrada in the Great Smoky Mountains National Park, USA: a preliminary report. Hydrobiologia, 558: 111-118.

Bertolani, R. \& L. Rebecchi. 1996. The tardigrades of Emilia (Italy). II. Monte Rondinaio. A multihabitat study on a high altitude valley of the northern Apennines. Zool. $J$. Linn. Soc., 116: 3-12.

Brose, U., N.D. Martinez, \& R.J. Williams. 2003. Estimating species richness: sensitivity to sample coverage and insensitivity to spatial patterns. Ecology, 84: 2364-2377.
Chazdon, R.L., R.K. Colwell, J.S. Denslow, \& M.R. Guariguata. 1998. Statistical methods for estimating species richness of woody regeneration in primary and secondary rain forests of NE Costa Rica. In: F. Dallmeier \& J.A. Comiskey (Eds), Forest biodiversity research, monitoring and modeling: Conceptual background and Old World case studies. Parthenon Publishing, Paris: 285-309.

Colwell, R.K. 1997. EstimateS: Statistical estimation of species richness and shared species from samples. Version 6. User's Guide and application published at: http://viceroy.eeb.uconn.edu/estimates.

Colwell, R.K. \& J.A. Coddington. 1994. Estimating terrestrial biodiversity through extrapolation. Phil. Trans. R. Soc. B, 345: 101-118.

Dastych, H. 1980. Tardigrades from the Tatra National Park. Polska Akademia Nauk Zaklad Zoologii Systematycznej i Doswiadczalnej. Monografie Fauny Polski. Vol. 9. Warszawa: $232 \mathrm{pp}$.

Riggin, G.T. 1962. Tardigrada of southwest Virginia: with the addition of a description of a new marine species from Florida. Virginia Agricul. Exp. Stn., Tech. Bull., 152: 1145 . 